\title{
ECOLOGY AND GEOLOGY OF THE GREATER YelloWSTONE AREA
}
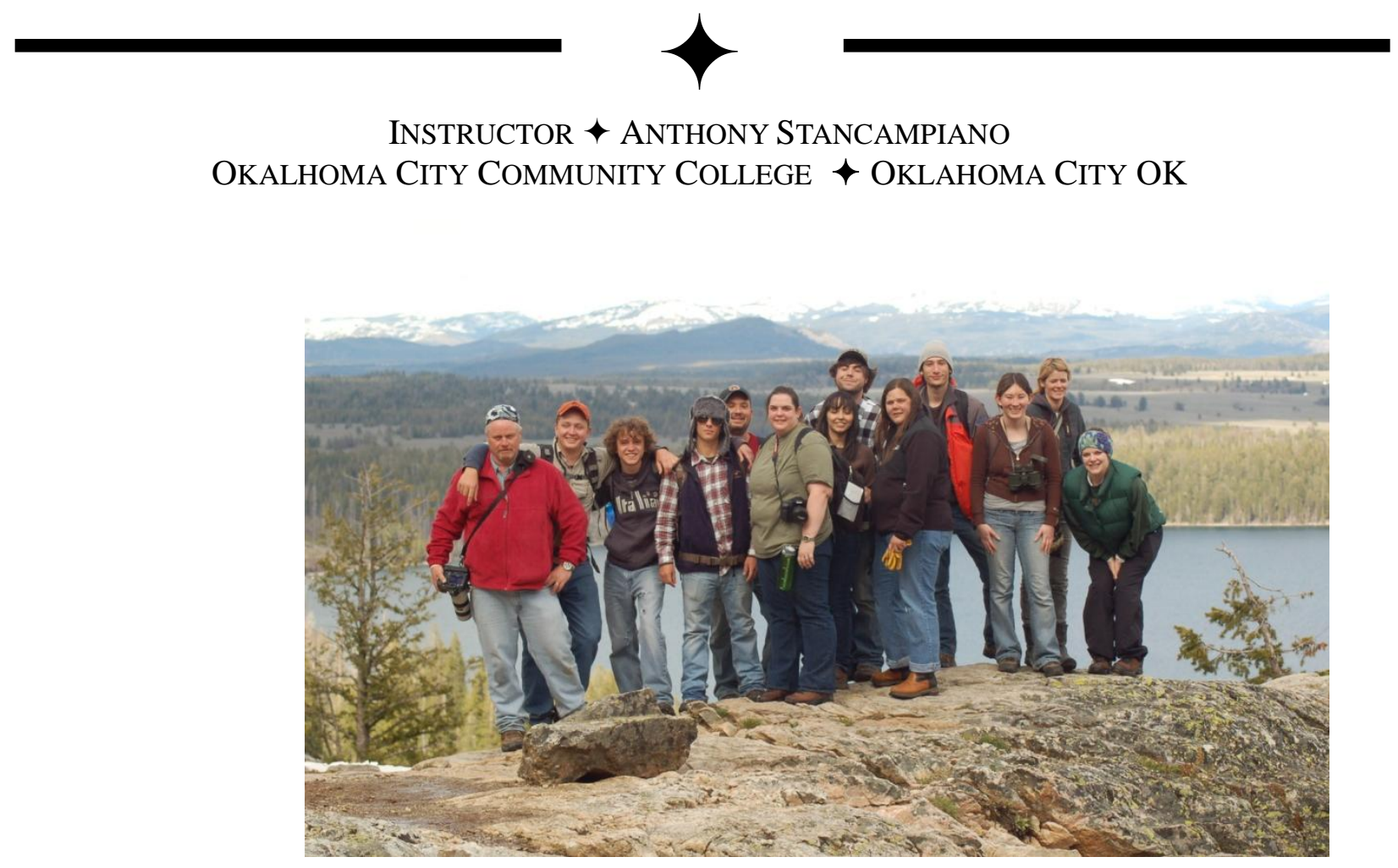

Each spring, near the end of May, students enrolled in BIO 2004- Special Topics in Ecology- at Oklahoma City Community College, are honored to experience 5-6 days at the AMK Ranch in Grand Teton National Park. Oklahoma City Community College (OCCC) is a metropolitan 2-year college serving the greater Oklahoma City area. OCCC is the $5^{\text {th }}$ largest campus in terms of FTE in the Oklahoma higher education system. The college serves a diversity of students including a traditional and nontraditional enrollment.

BIO 2004 is presented in a hybrid format offering. This particular section of Special Topics emphasizes the ecology of Greater Yellowstone. The online portion of the class consists of 4 units. Each unit deals with a specific area within ecology as it relates to Greater Yellowstone.
Unit one emphasizes physical ecology, basic geology, and the unique geology of the area. Unit two introduces the student to basic ecological principles and provides application to Yellowstone and Grand Teton communities and ecosystems. A review of evolution including natural selection and adaptation is also included. Unit three presents systematics, classification, and taxonomy. Students are introduced to cladistics and asked to construct a cladogram and classification using character cards. Unit four exposes students to field identification of plants and animals primarily. A major section of this unit is devoted to the large mammal and avian fauna associated with Greater Yellowstone. Additionally, students are taught the art of taking field notes and keeping a field journal in this unit. Following their study in each unit, students are asked to answer a series of questions pertaining to general topics of the unit with specific references to Greater Yellowstone. 

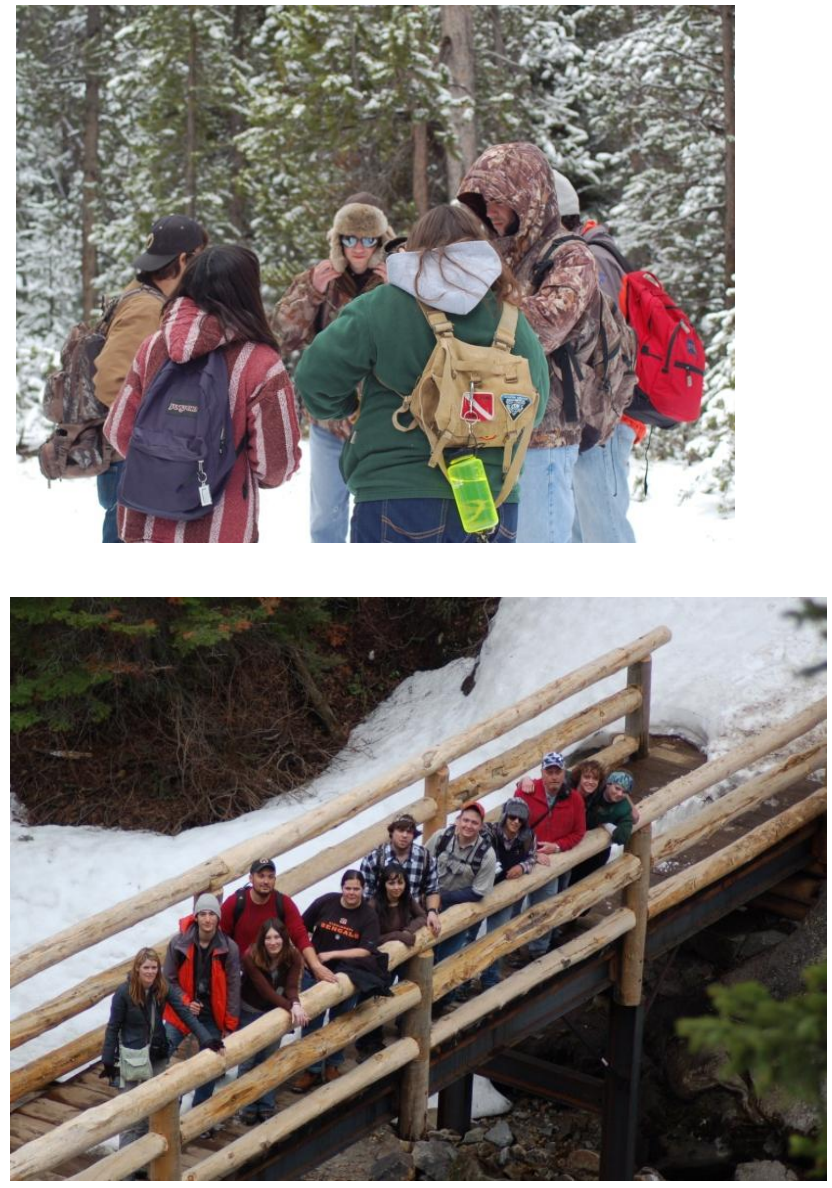

The field portion of the course takes place in Greater Yellowstone. Class members travel in 2 college vans/buses to the AMK Ranch. The entourage spends two nights camping, one night near Durango, Colorado and one night near Logan, Utah on the trip to Wyoming. This allows a mid afternoon arrival at AMK Ranch.

Each day in Wyoming is spent in a series of observational hikes highlighting those ecological principles, communities/ecosystems, and geological features that were studied in the online component. The AMK Ranch provides a centrally located headquarters for activities in Grand Teton National Park and Yellowstone National Park.

Specific locations visited include Lewis Falls, Lone Star Geyser, Fire Hole River and Canyon Drive, Upper/Middle/Lower Geyser basin, Norris, Mammoth Hot Springs, Grand Canyon of Yellowstone, Hayden Valley, Indian Pond, and Lamar Valley in Yellowstone; Jenny Lake, String Lake, Hidden Falls, Inspiration Point, Amphitheater Lake, Cascade Canyon Trail, Laurence S. Rockerfellow Preserve, and Willow Flats in Grand Tetons.
Special Topics in Ecology offers an opportunity for undergraduate students to experience, for the first time, the basics of field biology. Most students have never traveled out of the State of Oklahoma as adults. Many students have been inspired to continue their studies in biology at the university level due to participation in this course.

The AMK ranch and the University of Wyoming make this opportunity possible for students at OCCC. Dr. Henry Harlow and his staff, particularly Celeste Havener, facilitate our housing and accommodations at the AMK. Upon our arrival, Dr. Harlow addresses the students to inform them of general information, current events, personal safety in the parks, bear biology, history of the AMK, and related ecology/biology topics.

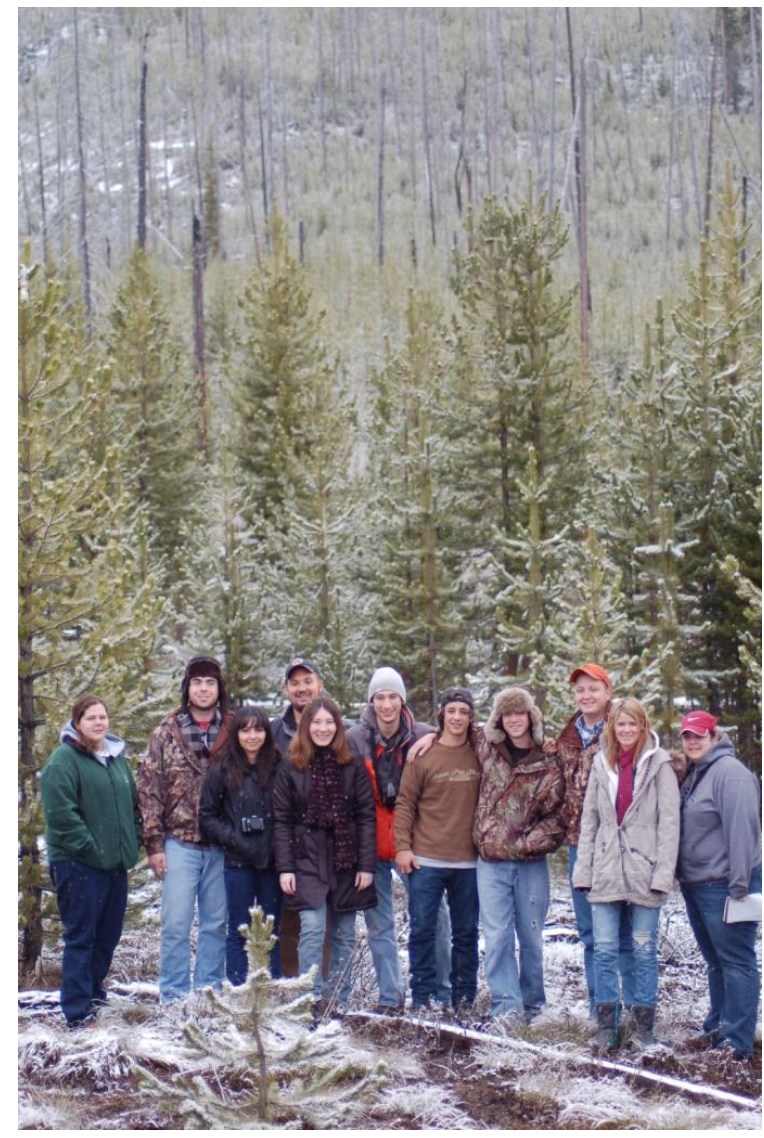

A special bond is formed between students who enroll in this course. In fact, at least one marriage has resulted from introductions made at AMK. In addition to ecological principles, many life lessons are learned on this journey. Students are enriched in the meaning of community and cooperation as they soak up the raw beauty and power of Greater Yellowstone. 